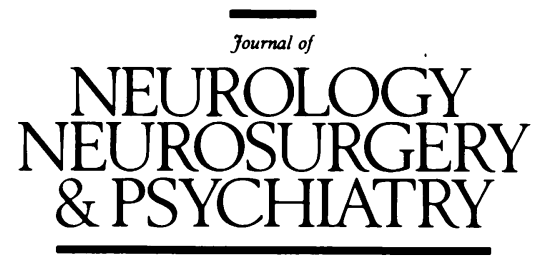

Editorial

\title{
Cost-effective investigation of patients with suspected transient ischaemic attacks
}

Each year in the United Kingdom about 25000 patients present to a doctor for the first time with a transient ischaemic attack of the brain or eye (TIA). ${ }^{1}$ These patients, as a group, are at increased risk of subsequent stroke and other serious vascular events. ${ }^{23}$ The risk can be reduced by control of vascular risk factors (such as hypertension ${ }^{4}$ and smoking), ${ }^{5}$ by long term antiplatelet therapy ${ }^{6}$ and by referral of appropriately selected patients for carotid endarterectomy. ${ }^{78}$ To be able to select appropriate treatments for appropriate patients, however, the following preliminary questions need to be answered: 1) Is it a TIA? (diagnosis); 2) Is it a carotid or vertebrobasilar artery distribution TIA? (anatomy); 3) What is the cause of the TIA? (aetiology)

The diagnosis of TIA depends almost entirely upon the clinical history and can therefore be subject to considerable interobserver disagreement, even among senior neurologists. ${ }^{9}$ The implications of misdiagnosis are significant because it is clearly neither appropriate nor costeffective to investigate non-TIA patients in the same way as TIA patients (for example, with carotid angiography).

The arterial territory (anatomy) of the TIA (carotid or vertebrobasilar) can usually, but not always, be distinguished from the clinical history. This distinction is not really necessary unless the patient is being considered for carotid angiography and endarterectomy.

The aetiology of the TIA is frequently suspected from the history and examination findings but rarely diagnosed with certainty. Special investigations have a major role in determining the cause of the TIA.They may also be used to identify treatable risk factors, to establish a baseline of prognostic factors and hence prognosis, and to exclude other diagnoses if that of TIA is in doubt. However, neurologists show enormous variation in the way they investigate TIA patients. ${ }^{1011}$ Whether this reflects different expectations of the tests (and different perceptions of where the results may lead), their local availability, consideration of profit to the provider, or uncertainties about the yield, costs, and risks of tests is uncertain. This review offers our strategy for cost-effective investigation of TIA patients.

\section{Yield}

The yield of a test is the proportion of the tests performed which detect a pathogenically relevant or potentially treatable condition that influences management. It depends critically on the doctor's selection criteria for ordering a test, the type of patient studied, the definition of the disease which the test is supposed to detect, and the degree of interobserver agreement in the diagnosis of the disease in question, in addition to the sensitivity, specificity and predictive values of the test itself.

The approximate percentage yield of each of the first line, or phase 1 , investigations (that is, those which we think are probably appropriate for all referred patients with suspected TIA) is shown in table 1 . The yield of second line, or phase 2 , investigations (that is, those which are appropriate in selected patients only [table 2]), in particular ultrasound and angiographic studies, is not only dependent upon the above factors (particularly selection criteria) but also the type of procedure and the expertise of the operator. The yield of the third line, or phase 3 , tests

Table 1 First line (phase 1) investigations appropriate for all referred TIA patients

\begin{tabular}{|c|c|c|c|c|}
\hline & & & $\begin{array}{l}\text { Direct Cost }(£) \\
\text { (labour/materials) }\end{array}$ & $\begin{array}{l}\text { Charge }(£) \\
\text { (Scottish Health Board })\end{array}$ \\
\hline \multicolumn{3}{|c|}{ Neurological consultation (30 minutes) } & 30 & $8 \cdot 75$ \\
\hline Baseline investigations & Treatable disorders detected & Yield (\%) & & \\
\hline Full blood count & anaemia, polycythaemia, leukaemia, thrombocythaemia & 1 & 1.65 & $9 \cdot 25$ \\
\hline ESR & vasculitis, endocarditis, hyperviscosity & 2 & $1 \cdot 20$ & $9 \cdot 25$ \\
\hline Plasma glucose & diabetes mellitus, hypoglycaemia & 5 & 0.84 & $9 \cdot 25$ \\
\hline Plasma cholesterol & hypercholesterolaemia & 45 & 0.79 & $9 \cdot 25$ \\
\hline VDRL, TPHA & syphilis, anticardiolipin antibody & $<1$ & 0.85 & $9 \cdot 25$ \\
\hline Urine analysis & diabetes, renal disease & 5 & 0.50 & $9 \cdot 25$ \\
\hline \multirow[t]{2}{*}{ Electrocardiogram (ECG) } & arrhythmia, left ventricular hypertrophy & 45 & $5 \cdot 00$ & $25 \cdot 00$ \\
\hline & & $\begin{array}{l}\text { Subtotal } \\
\text { Total }\end{array}$ & $\begin{array}{l}9 \cdot 74 \\
40\end{array}$ & $\begin{array}{l}80 \cdot 50 \\
90\end{array}$ \\
\hline
\end{tabular}

Footnote:

"Yield" refers to the approximate rate at which the test detects relevant conditions (which influence management or prognosis) in unselected TIA patients (estimated from references, ${ }^{23} 12$ and Oxfordshire Community Stroke Project data not published in ${ }^{2}$ ).

"Direct" costs are the estimated costs to the NHS of only the labour and materials needed to perform the test.

"Direct" costs are the estimated costs to the NHS of only the labour and mate 
Table 2 Investigations appropriate for selected TLA patients only

\begin{tabular}{|c|c|}
\hline Second line investigations (Phase 2) & Disorder detected \\
\hline $\begin{array}{l}\text { Urea and electrolytes } \\
\text { Thyroid function tests } \\
\text { Chest X ray } \\
\text { Cranial CT scan } \\
\text { Carotid ultrasound } \\
\text { Cerebral angiography } \\
\text { Echocardiography } \\
\text { Activated partial thromboplastin time (APTT) } \\
\text { Anticardiolipin antibody/Dilute Russell viper venom time (DRVVT) } \\
\text { Antinuclear antibodies } \\
\text { Serum protein, serum protein electrophoresis (SPEP), plasma viscosity } \\
\text { Haemoglobin electrophoresis } \\
\text { Electroencephalogram (EEG) }\end{array}$ & $\begin{array}{l}\text { Hyponatraemia or hypokalaemia (diuretics), renal impairment (hypertension) } \\
\text { Thyrotoxicosis (atrial fibrillation) } \\
\text { Calcified heart valves, enlarged heart pulmonary AVM } \\
\text { Structural intracranial lesion } \\
\text { Extracranial carotid stenosis } \\
\text { Carotid stenosis, arterial dissection, arteritis, AVM } \\
\text { Cardiac source of embolism } \\
\text { Antiphospholipid antibody (lupus anticoagulant) } \\
\text { Antiphospholipid antibody } \\
\text { Systemic vasculitis } \\
\text { Hypercoagulable state } \\
\text { Sickle cell trait, disease } \\
\text { Seizure disorder, structural intracranial lesion }\end{array}$ \\
\hline Third line investigations (Phase 3) & Disorder detected \\
\hline $\begin{array}{l}24 \text { hour ECG } \\
\text { Lipoprotein fractionation } \\
\text { Protein C. and S, antithrombin III, Thrombin time } \\
\text { Urine nitroprusside test } \\
\text { Plasma amino acid quantitation } \\
\text { Serum homocysteine (after méthionine load) } \\
\text { WBC alpha-galactosidase } \\
\text { Serum fluorescent treponemal antibody test (FTA) } \\
\text { Magnetic resonance imaging } \\
\text { Cerebrospinal fluid (CSF) } \\
\text { Temporal artery biopsy }\end{array}$ & $\begin{array}{l}\text { Cardiac arrhythmia } \\
\text { Hyperlipoproteinaemia } \\
\text { Deficiency state } \\
\text { Homocysteinuria (homozygote) } \\
\text { Homocysteinuria (homozygote) } \\
\text { Homocysteinuria (homozygote) } \\
\text { Fabry's disease } \\
\text { Meningovascular syphilis } \\
\text { Meningovascular syphilis } \\
\text { Occult structural intracranial lesion (e.g. AVM) } \\
\text { Giant cell arteritis }\end{array}$ \\
\hline
\end{tabular}

AVM: arteriovenous malformation.

(which are indicated only in selected patients in whom the cause of the TIA has not been established from the clinical evaluation and first and second line investigations [table $2]$ ) is very low (of the order of $\leqslant 1 \%$ ) in unselected patients and is very subject to the influence of selection in different cohorts.

\section{Cost}

It is extremely difficult, if not impossible, to obtain any accurate information about the direct cost to the National Health Service (NHS) of the investigation of TIA patients. It is uncertain whether they are known; probably they are not.

The two most commonly used approaches to costing are average bed-day costs and Health Board charges but these are inappropriate and can only be used as very rough estimates. ${ }^{1314}$ Average bed-day costs do not distinguish between bed-days in areas using different resources (such as the intensive-therapy unit and the neurology ward), nor do they embrace the costs incurred when beds are unoccupied. A charge is not an accurate reflection of cost because a proportion of the fee charged may be used for profit or to subsidise research or another item of health care. ${ }^{15}$

In the interests of simplicity, we have only considered direct variable and semi-variable material and labour costs and excluded the important direct fixed costs, indirect costs and intangible costs. ${ }^{14}$ Material costs include the costs of materials which are used, or disposed of, and the costs of equipment maintenance and depreciation. The cost of labour to the NHS involves a calculation involving the staff member's salary per unit time that is paid by the NHS and the time the staff member spends on each activity. On this basis, the cost of the consultant to the NHS per "procedure-hour" or "consultation-hour" is about $£ 60$ ( $£ 50000$ per year salary plus superannuation/ 40 weeks worked per year [six weeks annual leave, six weeks study leave] $/ 20$ hours per week performing procedures or consulting). The time taken to perform and report on an outpatient consultation is at least 30 minutes; an echocardiogram takes about 30 minutes, a Duplex carotid ultrasound up to 60 minutes, and cerebral angiography up to 90 minutes. The cost of a technician or nurse is about $£ 15$ per hour and the cost of a secretary is about $£ 6 \cdot 20$ per hour.
Table 1 shows some of the estimates that have been derived from annual departmental calculations performed locally in the Western General Hospital, Edinburgh, and from recent British publications. ${ }^{16}$ They are only approximate estimates that could be obtained within the confines of available knowledge of cost and expenditure, and are difficult to generalise widely. Alongside the estimated costs are the charges that our local health board makes for services given to private patients. Curiously, the charge for any kind of blood test is the same $(£ 9 \cdot 25)$, and indeed exceeds the charge for a patient consultation with a consultant $(£ 8 \cdot 75)$. We estimate the cost of the latter is about $£ 30$. Examples of other inconsistencies between estimated costs and charges include cranial CT (cost $£ 75$, charge $£ 134$ ), carotid ultrasound (cost $£ 85$, charge $£ 28$ ), echocardiograph (cost $£ 40$, charge $£ 93.75$ ), and 24 hour ECG (cost £40, charge $£ 125$ ). Cerebral angiography, performed as an outpatient, costs about $£ 200$ (charge $£ 135)$ but, in the UK it is usually carried out as an inpatient (for two nights). Our local health board charges the private patient $£ 193$ per night for a shared room; the charge incorporates all inpatient consultations and investigations.

The discrepancies between costs and charges are likely to have significant implications; the generally greater charges than costs of investigative tests are likely to have an inflationary effect while the unrealistically low charges, compared with costs, for clinical consultation are likely to have a very adverse effect on the time available for, and quality of, the consultation.

\section{Risks}

Besides a small quantity of radiation exposure associated with chest $x$-ray, plain cranial CT scan and cerebral angiography, the only significant radiological risks are those of cerebral angiography. We recently concluded that the permanent neurological complication rate (due to disabling stroke) of conventional cerebral angiography for patients with symptomatically-mild ischaemic cerebrovascular disease (such as TIA and non-disabling stroke) was about $1 \% .^{1819}$ The systemic complication rate of intravenous digital subtraction angiography (DSA) is unacceptably high (about $19 \%)^{18}$

Transoesophageal echocardiography (TOE) may sometimes be complicated by transient arrhythmias, transient 
unilateral vocal cord paralysis, or bacteraemia and rarely by oesophageal perforation. ${ }^{20}$ Prophylactic antibiotics are commonly administered to patients with known congenital or valvular heart disease undergoing TOE. Oesophageal varices, strictures, diverticuli and scleroderma are relative contraindications and caution should be taken in anticoagulated patients.

\section{Recommended investigation strategy}

We have not performed a cost-effectiveness study in the strict sense of the term (for example, compared one strategy with another or obtained a cost per year of life saved, or vascular event avoided), but have based the following recommendations on an assessment of the effectiveness and cost of widely used techniques for investigating TIA patients.

FIRST LINE INVESTIGATIONS (PHASE 1)

Although the yield from a full blood count, ESR, plasma glucose, cholesterol, VDRL and TPHA, urinalysis and ECG is relatively small when performed in all TIA patients unselectively, the cost of not identifying and treating the disorders that these tests may detect (table 1) probably exceeds that of performing the tests in all TIA patients, but no data are available.

As the proportion of deaths from coronary heart disease (the major cause of death in TIA patients) that can be attributed to hypercholesterolaemia is increased in patients with symptomatic vascular disease, it is probably costeffective to determine the plasma cholesterol in all TIA patients because they are likely to benefit more from lowering their plasma cholesterol than asymptomatic people of the same age and cholesterol level. ${ }^{2122}$

\section{SECOND LINE INVESTIGATIONS (PHASE 2)}

The choice of subsequent investigations (table 2) and the vigour with which they are pursued should be influenced by the patient's symptoms, age, general physical condition, and willingness to accept the risks and inconvenience associated with investigation and treatment, and by the cost-effectiveness of the investigation strategies (for both the health service and the patient).

The cost-effectiveness of testing the plasma urea and electrolytes is likely to be maximised if it is performed only in patients in whom there is doubt about the clinical diagnosis of TIA and in patients who are hypertensive or taking diuretic medication. Thyroid function tests should be limited to patients in atrial fibrillation. The chest $x$-ray requires a trip to hospital for some patients and is only indicated if the clinical or ECG findings show hypertension, left ventricular hypertrophy, or a possible cardiac source of embolism.

\section{Cranial CT scan}

The main purpose of cranial CT in suspected TIA patients is to exclude an underlying structural intracranial lesion (such as, a meningioma, glioma, subdural haematoma, giant aneurysm or vascular malformation) which may rarely present like a TIA. From limited data, the yield of CT appears to be about $1 \%$ in patients diagnosed as "TIA" 23-28 (and about $6 \%$ in patients with a clinical diagnosis of stroke). ${ }^{29}$ Although cranial CT reveals low density (presumed ischaemic) lesions in about a quarter of TIA patients, the lesions are distributed fairly evenly between the symptomatic and asymptomatic cerebral hemispheres and the clinical features, duration of attacks and the prognosis of patients with and without lesions on CT are similar. ${ }^{23}$ Therefore, in patients with suspected TIA, the aim of CT is not to identify areas of presumed cerebral infarction because it does not seem to matter whether TIA patients have a low density lesion on CT or not. Similarly, the aim of cranial CT is not to exclude intracerebral haemorrhage (ICH), as it is in patients with stroke, because definite ICH has not been reported as causing focal neurological symptoms lasting less than 24 hours. $^{30}{ }^{31}$ However, if a patient is seen during a TIA and has been taking anticoagulants or is being considered for antiplatelet or anticoagulant therapy, then CT is indicated to exclude ICH.

As the yield from routine screening of TIA patients with CT is very low for detecting structural lesions (1\%) and the cost of CT probably exceeds that of both the neurological consultation and baseline investigations combined, the concept of routine examination of every TIA patient with CT must be very carefully considered. The small minority of "TIA" patients with structural lesions, who would be "missed" by not performing a CT scan, are likely to continue to suffer symptoms (and return to the doctor) and their outcome is unlikely to be altered by a short delay in diagnosis. It is our impression that the small yield from CT is almost always in patients with carotid territory TIAs and there is some evidence to suggest that performing routine cranial CT in patients with vertebrobasilar territory TIAs is a waste of resources. ${ }^{25}$

We believe that cranial CT should be reserved for patients with continuing TIAs of the brain (but not the eye), particularly if they are in the carotid territory, and those who are being considered for carotid endarterectomy (to avoid operating on someone with a symptomatic meningioma for example). The CT scan should initially be a non-contrast study. Contrast should be used subsequently if a meningioma, giant aneurysm or AVM are suspected.

The data on the effectiveness of CT in TIA patients are poor and there is a need for a methodologically sound, prospective, multicentre study of this question, particularly in view of the considerable cost implications of a policy of "CT for all TIA patients".

\section{Carotid ultrasound and angiography}

Patients with recent carotid TIAs and more than $70 \%$ stenosis of the origin of the internal carotid artery on the symptomatic side who are fit for surgery are likely to benefit from ipsilateral carotid endarterectomy. ${ }^{78}$ Before carotid endarterectomy is considered, both the extracranial and intracranial carotid circulation must be imaged to the surgeon's satisfaction. Selective intra-arterial cerebral angiography is usually required, ${ }^{32}$ although carotid endarterectomy is occasionally performed on the basis of duplex carotid ultrasound ${ }^{33}$ or intravenous digital subtraction angiography ${ }^{34}$ (which we believe are inadequate). Angiography, however, is costly, it requires hospital admission, it is uncomfortable and carries a small but important risk. ${ }^{1819}$ It is therefore most important that angiography is not performed unnecessarily in patients who are not surgical candidates, such as those who have vertebrobasilar TIAs, or normal or completely occluded carotid arteries. The most cost-effective strategy to select patients for carotid angiography, before carotid endarterectomy, is to 1) Ensure, as far as it is possible, that the patient has carotidTIAs; 2) Ensure that the patient is medically fit and willing to consider carotid angiography and endarterectomy; and 3) Perform duplex carotid ultrasound before considering angiography. ${ }^{35}$ If duplex (or Doppler) ultrasonography suggests more than about $50 \%$ diameter stenosis at the origin of the symptomatic internal carotid artery, the patient should be considered for angiography. Although the sensitivity of duplex for detecting more than $50 \%$ diameter stenosis of the carotid artery is greater than 
$95 \%$, considerable difficulty may be encountered in distinguishing high-grade stenosis from complete occlusion of the carotid artery. ${ }^{36}{ }^{37}$ This distinction is important because patients with symptomatic high grade stenosis should be considered for carotid endarterectomy in contrast to patients with carotid occlusion. Although other non-invasive studies such as colour coded Doppler and magnetic resonance angiography may improve the yield in this area, ${ }^{3738}$ they are still being evaluated as research techniques and, for the time being, conventional cerebral angiography or intra-arterial digital subtraction angiography (IA-DSA) is required to confirm the presence or absence of complete carotid occlusion. Therefore, if the duplex suggests occlusion, angiography should still be peformed to exclude a tight stenosis. A selective intraarterial angiogram of the carotid system (extra- and intracranial) on the symptomatic side is required and if a "surgical" lesion is found, the contralateral carotid system should probably also be studied angiographically.

If the patient has a history of recent neck trauma or complains of neck pain, and arterial (carotid or vertebrobasilar) dissection is a diagnostic possibility, then angiography should also be considered. Otherwise, angiography is very rarely indicated for vertebrobasilar TIAs. One rare indication might be when symptoms suggestive of subclavian steal are accompanied by unequal brachial pulses and a systolic blood pressure difference of more than about $30 \mathrm{mmHg}$ between the two arms. Arch aortography should be performed if the patient is fit and willing to undergo the rather uncertain benefits of subclavian bypass surgery. Patients who continue to have vertebrobasilar TIAs despite optimal medical therapy should have a cranial CT scan. If the CT scan is unhelpful and an abnormality in the posterior fossa is still suspected, an MRI study should be considered because, although more expensive, the images of the posterior fossa are superior to CT. ${ }^{39}$ Vertebral angiography is probably not indicated as the results are unlikely to alter current management (at least in the UK).

\section{Echocardiography}

Transthoracic two-dimensional echocardiography (2DE) is more sensitive than $\mathrm{M}$-mode echocardiography and is now widely available. However, the resolution of $2 \mathrm{DE}$ is limited in obese patients and in those with emphysema, chest deformity or chest surgery. Also, 2DE fails to reliably detect atrial thrombi, particularly those located in the appendage. These limitations have been overcome to some extent by transoesophageal echocardiography (TOE), which images the left atrium well, but at the expense of suboptimal images of the cardiac apex and discomfort for the patient.

The yield from all types of echocardiography is minimal in TIA patients without clinical (history and examination), ECG or chest- $x$-ray evidence of heart disease but is up to $40 \%$ in TIA patients with known heart disease, ${ }^{3124041}$ particularly those who are studied with $\mathrm{TOE}^{42}$ and contrast echocardiography. ${ }^{43}$ Echocardiography (2DE) should therefore be reserved for: 1) Young patents (less than about 50 years of age) in whom cardiogenic embolism is suspected (because atheroma of the neck vessels is unlikely on clinical grounds or ruled out by duplex) and in whom no alternative cause has been identified; ${ }^{44}$ 2) Patients with clinical, ECG or chest $x$-ray evidence of a likely cardiac source of embolism; ${ }^{40}$ 3) The extraordinarily rare TIA patient with a family history of atrial myxoma or cardiomyopathy. ${ }^{45}$ Symptomatic patients with a high pretest probability of atrial thrombus (that is, atrial fibrillation) or patent foramen ovale who have a normal $2 \mathrm{DE}$, should be referred for TOE ${ }^{42}$ and contrast ${ }^{43}$ echocardio- graphy respectively. Whether management is likely to be influenced by the results, however, is unknown.

\section{Haematological screening}

Antiphospholipid antibodies are found in about $1-10 \%$ of TIA and stroke patients ${ }^{46-48}$ but the yield is influenced by patient section and the type of laboratory method used to detect antibodies (for example, the Russell viper venom time, kaolin clotting time and dilute activated partial thromboplastin time [APTT] are more sensitive than the VDRL, APTT, prothrombin time [PT] and anticardiolipin antibody tests). In patients with an unexplained TIA, particularly those who are relatively young (less than about 50 years), or have a strong personal or family history of premature arterial or venous occlusive disease, or an abnormality on the blood film (such as, thrombocytopenia), it is recommended to order initially a coagulation profile (to see if the APTT is prolonged), a test for the "lupus anticoagulant", such as the dilute Russell viper venom time, an anticardiolipin antibody test, and an antinuclear antibody test titre. ${ }^{48}$ The lupus anticoagulant should also be sought in patients with a (false) positive VDRL. Serum protein levels, protein electrophoresis and plasma viscosity measurements are indicated if an elevated ESR is discovered. ${ }^{48}$ Haemoglobin electrophoresis should be performed in black patients to detect sickle cell trait.

\section{Electroencephalography}

The only indication for EEG in patients with "TIA" is when the clinical diagnosis is in doubt and a diagnosis of partial (focal or localisation-related) seizures is a possibility. About $35 \%$ of patients with epilepsy consistently have specific epileptiform discharges on the waking interictal EEG and $50 \%$ do so on some occasion with repeated recording; about $15 \%$ never do. ${ }^{49}$ Although an EEG may help distinguish between small deep (lacunar) and cortical infarction, ${ }^{50}$ it has no unique role in identifying the cause of TIA, other than possibly to screen for structural lesions. However, cranial CT is a more effective way of doing this.

\section{THIRD LINE INVESTIGATIONS (PHASE 3)}

Optimal clinical criteria to select patients most likely to have a positive third line, or phase 3 , test in routine clinical practice have yet to be defined for almost all of them.

\section{Twenty four hour ECG}

The aim of prolonged ECG monitoring is to detect unsuspected, potentially embologenic arrhythmias (such as atrial fibrillation and sick sinus syndrome). In unselected TIA patients, the yield is very $\operatorname{low}^{40}$ and the test is relatively time consuming and therefore costly. In selected patients, particularly those with a history or ECG evidence of arrhythmia, the yield improves albeit only to about $1-2 \% .{ }^{1241}$ Prolonged ECG monitoring should be reserved for TIA patients a) With either palpitations during the attacks or with loss of consciousness accompanied by focal neurological signs; b) With suspicious standard ECGs; and c) With a possible cardioembolic source and no obvious cause after the first two phases of investigation. It should be emphasised however, that symptoms of focal neurological dysfunction due to cerebral ischaemia are almost never a result of systemic hypotension, such as that induced by a cardiac arrhythmia, unless severe occlusive carotid and/or vertebrobasilar artery disease co-exists.

\section{Ancillary investigations}

The prevention of coronary events should be as high a priority as the prevention of stroke in TIA patients because 
cardiac disease is the most common cause of death in TIA patients and the average annual mortality rate for TIA patients compares with, and indeed exceeds, the average annual mortality rate for patients with stable angina pectoris (about 4\%). ${ }^{2351}$

About $25 \%$ of TIA patients report previous symptoms of ischaemic heart disease (angina or myocardial infarction $)^{23}$ but although classic angina is highly correlated with coronary artery disease (CAD), less than one third of patients with severe CAD have classic symptoms, and about one half of patients suffering sudden cardiac death have no prior symptoms of heart disease. ${ }^{52}$ Asymptomatic CAD has been suspected by abnormal exercise ECGs in as many as $28 \%$ of patients with TIA $^{53}$ and by abnormal radionuclide ventriculogram in up to $41 \%$ of TIA patients. $^{54}$ It seems therefore that about half of all TIA patients harbour at least some degree of $\mathrm{CAD}$, of whom only about half are symptomatic.

If we investigate TIA patients for asymptomatic CAD and detect it, would patient management be altered? At present, TIA patients should be treated by control of vascular risk factors and long term antiplatelet agents, so the only additional treatment option that may be offered TIA patients (apart perhaps from beta blockers or calcium antagonists) is coronary angioplasty or coronary artery bypass grafting. If these invasive treatments can be shown to improve outcome in TIA patients above the effects of medical therapy then the benefits will need to be weighed against the additional costs and risks of both coronary angiography and intervention.

Studies are needed to determine whether it is costeffective to investigate some, or all, TIA patients with screening procedures such as exercise ECG, exercise radionuclide ventriculography and exercise or dipyridamole radionuclide angiography. ${ }^{55}$ At present, we do not recommend this practice unless it is as part of a methodologically-sound research study.

\section{Conclusion}

We have attempted to identify the most cost-effective strategy for investigating suspected TIA patients. It is not proposed as a rigid algorithm but as a set of guidelines which the physician can apply in the light of the patient's clinical findings, the patient's own wishes, and the outcome of discussions between the doctor and the patient about the balance between the risks and benefits of each particular course of action.

The single most important factor in the management of the TIA patient is an accurate clinical assessment. More time should be allocated for patient assessment in both general practice and in hospital outpatient clinics, in the United Kingdom at least. Having established the diagnosis of TIA, it would seem cost-effective to investigate all TIA patients with a full blood count, ESR, blood glucose, cholesterol, VDRL and TPHA, ECG, and urine analysis. The patient's symptoms, age, general physical condition, and willingness to be investigated and treated should be considered before embarking on further tests.

Prospective evaluation of the cost-effectiveness of the policy of "cranial CT scan for all TIA patients" and also "ancillary" cardiac investigations (for coexistent ischaemic heart disease) is required in TIA patients.

We thank Drs PAG Sandercock, MS Dennis and DW Dunbabin for reviewing the manuscript. Dr Hankey was supported by a grant from the Chest, Heart and Stroke Association.

GRAEME J HANKEY CHARLES P WARLOW

Department of Clinical Neurosciences, Western General Hospital, Edinburgh, UK

Correspondence to: Dr Graeme J Hankey, Department of Neurology, Royal Perth Hospital, Western Australia.
1 Dennis MS, Bamford JM, Sandercock PAG, Warlow CP. Incidence of transient ischaemic attacks in Oxfordshire, England. Stroke 1989;20: 333-9.

2 Dennis MS, Bamford JM, Sandercock PAG, Warlow CP. Prognosis of transient ischaemic attacks in the Oxfordshire Community Stroke Project. Stroke 1990;21:848-53.

3 Hankey GJ, Slattery JM, Warlow CP. The prognosis of hospital-referred transient ischaemic attacks. If Neurol Neurosurg Psychiatry 1991;54: 793-802.

4 Collins R, Peto R, MacMahon S, et al. Blood pressure, stroke and coronary heart disease. Part 2, short-term reductions in blood pressure: overview of randomised drug trials in their epidemiological context. Lancet $1990 ; 335: 827-38$.

5 Shinton R, Beevers G. Meta-analysis of relation between cigarette smoking and stroke. $B M \mathcal{F}$ 1989;298:789-94.

6 Antiplatelet trialists' collaboration: Secondary prevention of vascular disease by prolonged antiplatelet treatment. $B M \mathcal{F} 1988 ; 296: 320-31$

European Carotid Surgery Trialists' Collaborative Group. MRC European Carotid Surgery Trial: interim results for symptomatic patients with severe $(70-99 \%)$ or with mild $(0-29 \%)$ carotid stenosis. Lancet 1991 ; 337:1235-43.

8 North American Symptomatic Carotid Endarterectomy Trial (NASCET) collaborators. Beneficial effect of carotid endarterectomy in symptomatic patients with high-grade carotid stenosis. N Engl f Med 1991;325: 445-53.

9 Kraaijeveld CL, van Gijn J, Schouten HJA, Staal A. Interobserver agreement for the diagnosis of transient ischaemic attacks. Stroke 1984;15:723-5.

10 Hopkins A, Menken M, DeFriese GH, Feldman RG. Differences in strategies for the diagnosis and treatment of neurologic disease among British and American neurologists. Arch Neurol 1989;46:1142-8.

11 UK-TIA Study Group: Variation in the use of angiography and carotid endarterectomy by neurolgists in the UK-TIA Aspirin Trial. BMF 1983;286:514-7.

12 Bogousslavsky J, Hachinski V, Boughner DR, Fox AJ, Vinuela F, Barnett HJM. Cardiac and arterial lesions in carotid transient ischaemic attacks. Arch Neurol 1986;43:223-8.

13 Detsky AS, Naglie G. A clinician's guide to cost-effectiveness analysis. Ann Intern Med 1990;113:147-54.

14 Hall J, Mooney G. What every doctor should know about economics. Med f A ust 1990;152:29-31.

15 Finkler SA. The distinction between cost and charges. Ann Intern Med 1982;96:102-9.

16 Tarbit IF. Costing clinical biochemistry services as part of an operational management budgeting system. $f$ Clin Pathol 1986;39:817-27.

17 Tarbit IF. Laboratory costing system based on number and type of test: its association with the Welcan workload measurement system. $f$ Clin Pathol 1990;43:92-7.

18 Hankey GJ, Warlow CP, Sellar RJ. Cerebral angiographic risk in mild cerebrovascular disease. Stroke 1990;21:209-22.

19 Hankey GJ, Warlow CP, Molyneux AJ. Complications of cerebral angiography for patients with mild carotid territory ischaemia being considered for carotid endarterectomy. F Neurol Neurosurg Psychiatry 1990;53: 542-8.

20 Fisher EA, Goldman ME: Transesophageal echocardiography: a new view of the heart. Ann Int Med 1990;113:91-3.

21 Rubin SM, Sidney S, Black DM, Browner WS, Hulley SB, Cummings SR. High blood cholesterol in elderly men and the excess risk for coronary heart disease. Ann Intern Med 1990;113:916-20.

22 Tunstall-Pedoe $H$. Who is for cholesterol testing? BMf 1989;298:1593-4

23 Dennis MS, Bamford JM, Sandercock PAG, Molyneux AJ, Warlow CP. Computed tomography in patients with transient ischaemic attacks: when is a transient ischaemic attack not a transient ischaemic attack? $¥$ Neurol is a transient isch

24 Weisberg LA, Nice CN. Intracranial tumours simulating the presentation of cerebrovascular syndromes. Early detection with cerebral computed tomography. Am $\mathcal{F}$ Med 1977;63:517-24.

25 Kingsley DPE, Radue EW, Du Boulay EPGH. Evaluation of computed tomography in vascular lesions of the vertebrobasilar territory. $\mathcal{F}$ Neurol, Neurosurg Psychiatry 1980;43:193-7.

26 Sotaniemi KA, Pyhtinen J, Myllyla VV. Correlation of clinical and computed tomographic findings in stroke patients. Stroke 1990;21:1562-6.

27 Rolak LA, GilmerW, Strittmatter WJ. Low yield in the diagnostic evaluation of transient ischaemic attacks. Neurology 1990;40:747-8.

28 Kinkel WR, Jacobs L. Computerised axial transverse tomography in cerebrovascular disease. Neurology 1976;26:924-30.

29 Hankey GJ, Warlow CP. The role of imaging in the management of cerebral and ocular ischaemia. Neuroradiology 1991:33:381-90.

30 Dennis MS, Bamford JM, Molyneux AJ, Warlow CP. Rapid resolution of signs of primary intracerebral haemorrhage in 'computed tomograms of the brain. BMf 1987;295:379-81.

31 Scott WR, Miller BR. Intracerebral haemorrhage with rapid recovery. Arch Neurol 1985;42:133-6.

32 Murie JA, Morris PJ. Carotid endarterectomy in Great Britain and Ireland. Br 7 Surg 1986;73:867-70

33 Ricotta JJ, Holen J, Schenk E, et al. Is routine angiography necessary prior to carotid endarterectomy? FVasc Surg 1984;1:96-102.

34 Cebul RD, Paulus RA. The failure of intravenous subtraction angiography in replacing carotid angiography. Ann Intern Med 1986;104:572-4.

35 Hankey GJ, Warlow CP. Symptomatic carotid ischaemic events: safest and most cost-effective way of selecting patients for angiography before carotid endarterectomy. $B M \mathcal{F}$ 1990;300:1485-91

36 Lewis BD, James M, Welch TJ. Current applications of duplex and colour flow doppler ultrasound imaging: carotid and peripheral vascular disease. Mayo Clin Proc 1989;64:1147-57.

37 Carroll BA. Carotid sonography. Radiology 1991;178:303-13.

38 Caplan LR, Wolpert SM. Angiography in patients with occlusive cerebrovascular disease: views of a stroke neurologist and neuroradiologist. $A$ fNR 1991;12:593-601.

39 Davis SM, Donnan GA, Tress BM, Kiers L, Dowling R, Rossiter SC. Magnetic resonance imaging in posterior circulation infarction: impact on diagnosis and management. Aust NZ f Med 1989;19:219-25.

40 De Bono DP, Warlow CP. Potential sources of emboli in patients with presumed transient cerebral or retinal ischaemia. Lancet 1981;i:343-6.

41 Come PC, Riley MF, Bivas NK. Roles of echocardiography and arrhythmia monitoring in the evaluation of patients with suspected systemic embolism. Ann Neurol 1983;13:527-31. 
42 Pop G, Sutherland GR, Koudstaal PJ, Sit TW, de Jong G, Roelandt JRTC. Transesophageal echocardiography in the detection of intracardiac embolic sources in patients with transient ischaemic attacks. Stroke 1990;21:560-5.

43 Jeanrenaud X, Kappenberger L. Patent foramen ovale and stroke of unknown origin. Cerebrovasc Dis 1991;1:184-92.

44 Biller J, Johnson MR, Adams HP Jr, et al. Echocardiographic evaluation of young adults with nonhaemorrhagic cerebral infarction. Stroke 1986;17: young adult $608-12$.

45 Natowicz M, Kelley RI. Mendelian aetiologies of stroke. Ann Neurol 1987;22:175-92.

46 Hess DC, Krauss J, Adams RJ, Nichols FT, Zhang DI, Rountree HA. Anticardiolipin antibodies: A study of frequency in TIA and stroke. Neurology 1991;41:525-8.

47 Montalban J, Codina A, Ordi J, Vilardell M, Khamashta MA, Hughes GRV. Antiphospholipid antibodies in cerebral ischaemia. Stroke 1991;22 750-3.

48 Hart RG, Kanter MC: Haematological disorders and ischaemic stroke. A selective review. Stroke 1990;21:1111-21.
49 Chadwick D: Diagnosis of epilepsy. Lancet 1990;336:291-5.

50 MacDonell RAL, Donnan GA, Bladin PF, Berkovic SF, Wriedt CHR. The electroencephalogram and acute ischaemic stroke: distinguishing cortical from lacunar infarction. Arch Neurol 1988;45:520- 4.

51 Kent KM, Rosing DR, Wewls CJ, Lipson L, Bonno R, Epstein S. Prognosis of asymptomatic or mildly symptomatic patients with coronary heart disease. Am 7 Cardiol 1982;49:1823-31.

52 Adams HP Jr, Kassell NF, Mazuz H. The patient with transient ischaemic attacks-Is this the time for a new therapeutic approach? Stroke attacks-Is this

53. Di Pasquale GD, Andreoli A, Pinelli G, et al. Cerebral ischaemia and asymptomatic coronary artery disease: A prospective study of 83 patients. Stroke 1986;17:1098-101.

54 Rokey R, Rolak L, HaratiY, Kutka N, Verain M. Coronary artery disease in patients with cerebrovascular disease: a prospective study. Ann Neurol 1984;16:50-53.

55 Sirna S, Biller J, Skorton DJ, Seabold JE. Cardiac evaluation of the patien with stroke. Stroke 1990;21:14-23.

\section{Neurological stamp}

\section{René Descartes 1596-1650}

Descartes was a French mathematician, philosopher and scientist. He saw the human body purely in terms of a mechanical contrivance-"a machine made by the hand of God, incomparably better than any machine of human invention". The mind was considered a separate entity interacting with the body via the pineal gland which was believed to be the seat of the soul. The soul was directly related to the vital mechanics of the body from which it received impressions and it was able to control certain movements. Descartes believed that the pineal and the soul existed only in humans.

He formulated optical laws for refraction, compared the eye to a camera obscura, and showed accommodation was due to changes in the shape of the lens. Descartes described one of the earliest concepts in neurophysiology, unconscious reflex action. In his treatise Des passions de l'âme (1649) he noted a feigned blow to the eyes caused a blink. In De Homine, published in 1662, some years after his death and considered to be the first textbook of physiology, there is a diagram of a child reflexly withdrawing its finger from a hot object.

Descartes died in Stockholm "in the land of bears, among rocks and ice". He was invited to the court of Sweden by Queen Christina to discuss philosophy which they apparently did at 4 o'clock in the morning. France commemorated him with this stamp, in 1937, on the third centenary of the publication of his work Discours de la Méthode. (Stanley Gibbons No 575, Scott No 331).

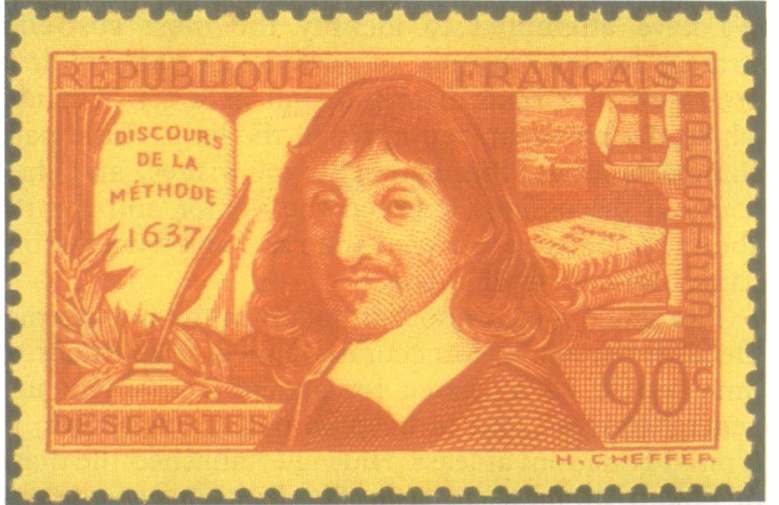

